\title{
openheart Mortality and high risk of major adverse events in patients with COVID-19 and history of cardiovascular disease
}

\author{
Elena Tessitore (1) , ${ }^{1}$ David Carballo, ${ }^{1}$ Antoine Poncet, ${ }^{2}$ Nils Perrin, ${ }^{1}$ \\ Cedric Follonier (10 , ${ }^{1}$ Benjamin Assouline, ${ }^{3}$ Sebastian Carballo, ${ }^{4}$ \\ François Girardin, ${ }^{5,6}$ Francois Mach ${ }^{1}$
}

\begin{abstract}
- Additional supplemental material is published online only. To view, please visit the journal online (http://dx.doi.org/10. 1136/openhrt-2020-001526).

To cite: Tessitore E, Carballo D, Poncet $\mathrm{A}$, et al. Mortality and high risk of major adverse events in patients with COVID-19 and history of cardiovascular disease. Open Heart 2021;8:e001526. doi:10.1136/ openhrt-2020-001526
\end{abstract}

$\mathrm{ET}, \mathrm{DC}, \mathrm{FG}$ and FM contributed equally.

Received 20 November 2020 Revised 1 February 2021 Accepted 19 March 2021

Check for updates

(c) Author(s) (or their employer(s)) 2021. Re-use permitted under CC BY-NC. No commercial re-use. See rights and permissions. Published by BMJ.

For numbered affiliations see end of article.

Correspondence to Dr Francois Mach; Francois. Mach@hcuge.ch

\section{ABSTRACT}

Objective History of cardiovascular diseases (CVDs) may influence the prognosis of patients hospitalised for COVID-19. We investigated whether patients with previous CVD have increased risk of death and major adverse cardiovascular event (MACE) when hospitalised for COVID-19.

Methods We included 839 patients with COVID-19 hospitalised at the University Hospitals of Geneva. Demographic characteristics, medical history, laboratory values, ECG at admission and medications at admission were collected based on electronic medical records. The primary outcome was a composite of in-hospital mortality or MACE.

Results Median age was 67 years, $453(54 \%)$ were males and 277 (33\%) had history of CVD. In total, 152 (18\%) died and $687(82 \%)$ were discharged, including $72(9 \%)$ who survived a MACE. Patients with previous CVD were more at risk of composite outcomes 141/277 (51\%) compared with those without CVD 83/562 (15\%) (OR=6.0 (95\% Cl 4.3 to $8.4), p<0.001)$. Multivariate analyses showed that history of CVD remained an independent risk factor of in-hospital death or MACE $(0 \mathrm{R}=2.4 ;(95 \% \mathrm{Cl} 1.6$ to 3.5$))$, as did age (OR for a 10-year increase $=2.2(95 \% \mathrm{Cl} 1.9$ to 2.6$)$ ), male gender ( $\mathrm{OR}=1.6(95 \% \mathrm{Cl} 1.1$ to 2.3$))$, chronic obstructive pulmonary disease $(\mathrm{OR}=2.1(95 \% \mathrm{Cl} 1.0$ to 4.2$))$ and lung infiltration associated with COVID-19 at CT scan $(\mathrm{OR}=1.9$ (95\% Cl 1.2 to 3.0)). History of CVD (OR=2.9 (95\% Cl 1.7 to 5)), age ( $\mathrm{OR}=2.5(95 \% \mathrm{Cl} 2.0$ to 3.2$))$, male gender ( $\mathrm{OR}=1.6(95 \% \mathrm{Cl} 0.98$ to 2.6$)$ ) and elevated $\mathrm{C}$ reactive protein (CRP) levels on admission (OR for a $10 \mathrm{mg} / \mathrm{L}$ increase $=1.1(95 \% \mathrm{Cl} 1.1$ to 1.2)) were independent risk factors for mortality.

Conclusion History of CVD is associated with higher inhospital mortality and MACE in hospitalised patients with COVID-19. Other factors associated with higher in-hospital mortality are older age, male sex and elevated CRP on admission.

\section{INTRODUCTION}

SARS-CoV-2 has been identified as the causative virus responsible for the pneumonia named COVID-19 by the WHO. ${ }^{1}$

COVID-19 rapidly turned into a pandemic and has become a severe burden to health

\section{Key questions}

What is already known about this subject?

- COVID-19 patients with history of cardiovascular diseases are more at risk of complications.

What does this study add?

- We aim to provide new knowledge regarding the relationship between COVID-19 outcomes and cardiovascular disease. This study reports that hospitalised COVID-19 patients with cardiovascular diseases should be identified as a more vulnerable population during the COVID-19 pandemic.

How might this impact on clinical practice?

- In hospitalised patients with COVID-19, history of cardiovascular disease, advanced age, male sex and chronic obstructive pulmonary disease are all independent risk factors of in-hospital death or major adverse cardiovascular event for hospitalised patients with COVID-19. When considering all-cause in-hospital death, advanced age, male sex and elevated $\mathrm{C}$ reactive protein levels on admission are all independent risks factors. These findings help to identify distinct inpatient archetypes and trajectories during and after hospitalisation.

systems worldwide, with important social and economic repercussions. Cases of new COVID-19 infections have been confirmed in more than 220 countries or regions around the world, and America has been the continent with most cases so far. ${ }^{2}$ It has been reported that pre-existing cardiovascular disease (CVD) may contribute to adverse early clinical outcomes and that COVID-19 infection may have longer term implications for overall cardiovascular (CV) health. ${ }^{3}$

The American College of Cardiology and the European Society of Cardiology also pointed out that patients with $\mathrm{CV}$ risk factors and established CVD represent a vulnerable population when suffering from COVID$19 .^{4}$ Recent studies showed that the risk of in-hospital death among patients with 
severe COVID-19 was significantly associated with elderly, inflammatory response and CV comorbidities. ${ }^{67}$

Several potential mechanisms were explored to explain the more severe course of the disease in patients with underlying $\mathrm{CV}$ risk factors and $\mathrm{CVD} .^{8}$ In particular, the role of ACE inhibitors and angiotensin receptors blockers (ARBs) has been discussed as one of the potential entry paths for SARS-CoV-2 in epithelial cells via the ACE2 receptor. $^{9}$

We aimed to investigate composite outcomes, as of in-hospital mortality and/or major adverse cardiovascular events (MACEs) in hospitalised patients with COVID-19 based on the presence or absence of previous CVD.

\section{METHODS}

\section{Study design}

The Geneva Covid-19 CVD Study (ClinicalTrials.gov identifier: NCT04384029) is an observational, monocentric cohort study.

In order to provide the best quality of care and standardised management of inpatients with COVID-19, the Swiss Public Health Authorities decided to centralise all health system resources for patients with COVID-19, and for the Canton of Geneva, the University Hospitals of Geneva was selected as the only COVID-19 referral centre.

Patients or the public were not involved in the design, or conduct, or reporting, or dissemination plans of our research.

\section{Study participants}

We included all patients consecutively admitted at the University Hospitals of Geneva with a confirmed COVID-19 diagnosis between 26 February 2020 and 26 April 2020 and who were discharged or had died by 5 June 2020. Patients still hospitalised on 5 June 2020 could not be included as their data were not yet available for analysis.

Inclusion criteria were: all subjects $\geq 18$ years tested positive to SARS-CoV-2 and exhibiting COVID-19 symptoms $^{10}$ that required hospitalisation. We excluded all patients who were found positive for SARS-CoV-2 without COVID-19 symptoms who were hospitalised for other reasons than COVID-19. For all hospitalised patients, we used the general informed consent form documented in the patient chart and excluded those not able to provide informed consent.

The diagnostic tool of choice to detect SARS-CoV-2 infection was a nasopharyngeal swab specimen (reverse transcriptase PCR assay). Details on diagnostic tools and hospitalisation criteria are described in the online supplemental material.

\section{Data collection}

Demographics data, history of CVD, presence of other comorbidities, CV risks factors, blood tests at admission, as well as ECG and treatment on admission were collected according to electronic medical records. Data for all
MACE, as well as death were gathered from discharge summaries or progress notes according to the doctor in charge of the patient.

Abstractors were four registered and certified physicians and nurses trained to enter standard data elements into REDCap, a secure, free web application for building and managing databases.

Data were extracted through validated automated feeds form electronic health records and manually by a study team trained on uniform sources for the study variables. The Geneva Covid-19 CVD Study is reported in accordance with the Strengthening the Reporting of Observational Studies in Epidemiology reporting guideline.

\section{Study definitions}

MACEs were defined as: CV death, heart failure (defined as acute heart failure either in a patient with or without a medical history of heart failure, with transthoracic echocardiography with left ventricle ejection fraction $<50 \%$, heart failure symptoms and elevated NT-pro BNP (N-terminal-pro brain natriuretic peptide) according to the European guidelines), ${ }^{11}$ non- fatal myocardial infarction (MI) either STEMI (ST elevation myocardial infarction) or NSTEMI (non-ST elevation myocardial infarction) as defined by the European Society of Cardiology ${ }^{12}$; nonfatal stroke (ischaemic or haemorrhagic stroke); and major arrhythmia (defined as any of the following: atrial fibrillation, atrial flutter, ventricular tachycardia and ventricular fibrillation).

History of CVD was defined as: history of acute coronary syndrome (either history of STEMI, NSTEMI or unstable angina), as well as history of any of the following: stable angina, coronary artery bypass, peripheral artery disease, ischaemic or haemorrhagic stroke or transitory ischaemic attack (TIA), history of arrhythmia (atrial fibrillation, atrial flutter and ventricular tachycardia), history of heart failure, history of myocarditis or pericarditis.

$\mathrm{CV}$ risk factors as well as every diagnosis are defined in the online supplemental material.

\section{Study outcomes}

The primary outcome was a composite outcome defined as in-hospital death or in-hospital MACE.

Secondary outcomes were: in-hospital death, MACE, myocarditis, venous thrombotic complications, total hospital length of stay, intensive care unit (ICU) and intermediate care unit (IMCU) stay and length of stay, and rehabilitation length of stay.

\section{Statistical analysis}

Power considerations: we hypothesised that around 600 patients would have been hospitalised owing to COVID19 , of whom $10 \%$ would have a history of CVD. Assuming that the proportion of patients presenting the composite outcome would be $18 \%$ in patients with history of CVD and $7 \%$ in patients without history of CVD $(\mathrm{OR} \approx 3)$, the present study had $80 \%$ power at a two-sided 0.05 level. 
Patient characteristics, laboratory values and medication at admission were described as frequencies and percentages for qualitative data and as median (Q1-Q3) for quantitative data. Methods of parameter comparisons according to clinical status, as well as clinical outcome comparisons according to history of CVD, are further detailed in the online supplemental material.

The study's main objective was to assess the effect of history of CVD on the composite MACE or death using logistic regression. Effect of history of CVD on death only was also assessed using logistic regression. History of CVD was expressed as crude and adjusted OR with a 95\% CI. Restricted lists of potential confounding factors were defined a priori: (1) when analysing the composite outcome, the list consisted of age, sex, CT scan findings, hypertension, obesity (body mass index (BMI) $\geq 30 \mathrm{~kg} / \mathrm{m}^{2}$ ), dyslipidaemia, diabetes (type I or II), active smoking, chronic obstructive pulmonary disease (COPD) and obstructive sleep apnoea; (2) when analysing death status, the list was further extended with values at admission for creatinine, $\mathrm{C}$ reactive protein (CRP), AST/ALT (aspartate transaminase/alanine transaminase) ratio and anaemia. Estimation of regression model coefficients was based on a complete case analysis, with parameters presenting more than $5 \%$ of missing data being subsequently removed. No multiple imputation methods were used. Log-linearity assumption was graphically assessed, both in univariate and multivariate analyses. Sensitivity analyses including parameters formerly removed due to missing data were finally performed in order to assess the robustness of the results (online supplemental material).
Statistical significance was assessed at the two-sided 0.05 level for all analyses. All analyses were performed using $\mathrm{R}$ software, V.4.0.2 (R Foundation for Statistical Computing, Vienna; www.R-project.org).

\section{RESULTS}

Between 26 February 2020 and 26 April 2020, 898 patients with COVID-19 were hospitalised in our centre, of which 839 were included in our study (figure 1). Median age was 67 years, $453(54 \%)$ were males, 392 (47\%) had hypertension, 206 (27\%) were obese (BMI $\left.\geq 30 \mathrm{~kg} / \mathrm{m}^{2}\right), 205(24 \%)$ had dyslipidaemia, 169 (20\%) had diabetes (predominantly type II) and 37 (4\%) were active smokers. The most common symptom at admission was dyspnoea or oxygen desaturation $(67 \%, \mathrm{n}=566)$, and patients frequently presented with fever (73\%), cough (62\%), asthenia (33\%), gastrointestinal symptoms (25\%) and myalgia (22\%). Only eight patients $(1 \%)$ presented an acute coronary syndrome (ACS) at admission.

Medical history of CVD was found in 277 patients (33\%). Specifically, 89 patients had a history of ACS $(11 \%)$, either STEMI, NSTEMI or unstable angina. A total of $104(12 \%)$ had a history of arrhythmia (mainly atrial fibrillation), 75 (9\%) had a medical history of stroke or transient ischaemic attack, $60(7 \%)$ had a history of heart failure and $38(5 \%)$ had a history of peripheral artery disease (table 1). Other most relevant comorbidities were moderate or severe chronic kidney failure $(11 \%)$, dementia (10\%), obstructive sleep apnoea (8\%), asthma $(7 \%)$, COPD (6\%), malnutrition $(6 \%)$ (definitions are

898 symptomatic patients tested positive for SARS-CoV-2 and hospitalized for Covid-19

at the University Hospitals of Geneva between February 26, 2020 and April 26, 2020.

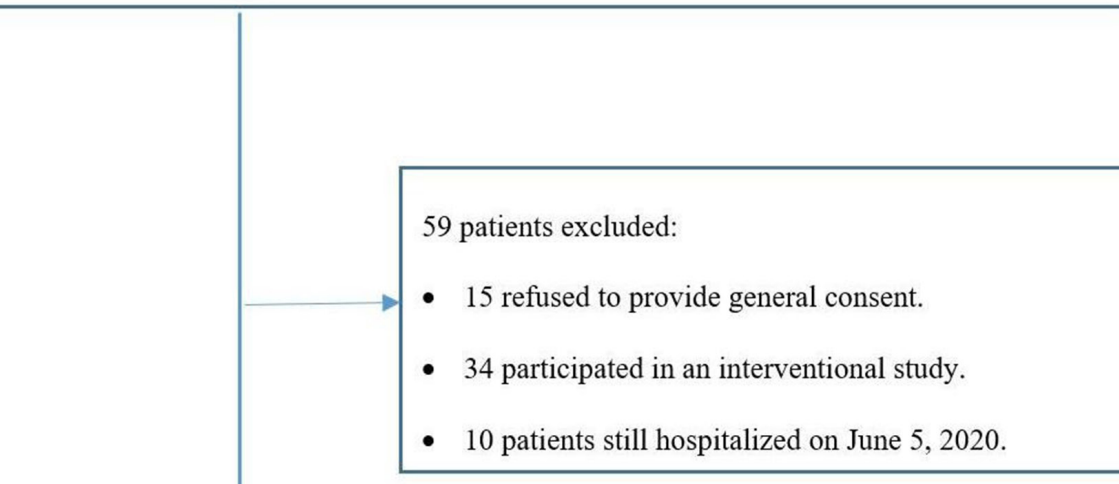

839 patients included in the study

- 152 died in hospital

- 687 were discharged by June 5,2020

Figure 1 Participants inclusion and exclusion. 
Table 1 Patient characteristics

\begin{tabular}{|c|c|c|c|c|c|}
\hline Variable & $\begin{array}{l}\text { All patients } \\
(n=839)\end{array}$ & $\begin{array}{l}\text { No events } \\
(n=615)\end{array}$ & $\begin{array}{l}\text { Survived with MACE* } \\
(\mathrm{n}=72)\end{array}$ & $\begin{array}{l}\text { Died } \\
(n=152)\end{array}$ & $P$ value \\
\hline Age (year) median (Q1-Q3) & $67(54-81)$ & $60(50-75)$ & $80(68-86)$ & $84(76-88)$ & $<0.001$ \\
\hline Male & $453(54)$ & $321(52)$ & $36(50)$ & $96(63)$ & 0.04 \\
\hline \multicolumn{6}{|l|}{ Symptoms at admission } \\
\hline Fever & $610(73)$ & $461(75)$ & $46(64)$ & $103(68)$ & 0.04 \\
\hline Dyspnoea or oxygen desaturation & $566(67)$ & $404(66)$ & $46(64)$ & $116(76)$ & 0.03 \\
\hline Cough & $519(62)$ & $398(65)$ & $42(58)$ & 79 (52) & 0.01 \\
\hline Asthenia & $279(33)$ & $211(34)$ & $23(32)$ & $45(30)$ & 0.53 \\
\hline Gl symptoms & $212(25)$ & $183(30)$ & $10(14)$ & $19(12)$ & $<0.001$ \\
\hline Myalgia & $188(22)$ & $167(27)$ & $12(16)$ & $9(6)$ & $<0.001$ \\
\hline Headache & $121(14)$ & $113(18)$ & $4(6)$ & $4(3)$ & $<0.001$ \\
\hline Expectorations & $120(14)$ & $97(16)$ & $9(12)$ & $14(9)$ & 0.11 \\
\hline Altered smell or taste sensation & $62(7)$ & $56(9)$ & $3(4)$ & $3(2)$ & 0.006 \\
\hline Runny nose & $51(6)$ & $46(7)$ & $2(3)$ & $3(2)$ & 0.01 \\
\hline \multicolumn{6}{|l|}{ Cardiovascular risk factors } \\
\hline Hypertension & $392(47)$ & $249(40)$ & $48(67)$ & $95(62)$ & $<0.001$ \\
\hline Obesity† & $206(27)$ & $153(28)$ & $17(25)$ & $36(24)$ & 0.62 \\
\hline Dyslipidaemia & $205(24)$ & $131(21)$ & $27(38)$ & $47(31)$ & 0.001 \\
\hline Diabetes (type I and II) & $169(20)$ & $105(17)$ & $17(24)$ & $47(31)$ & $<0.001$ \\
\hline Smoking & $37(4)$ & $26(4)$ & $5(7)$ & $6(4)$ & 0.53 \\
\hline Physical inactivity & $22(3)$ & $9(1)$ & $2(3)$ & $11(7)$ & $<0.001$ \\
\hline Stress & $6(1)$ & $6(1)$ & - & - & 0.77 \\
\hline Familial history & $6(1)$ & $4(1)$ & $2(3)$ & - & 0.11 \\
\hline Familial hypercholesterolaemia & $5(1)$ & $5(1)$ & - & - & 0.74 \\
\hline Medical history of CV disease & $277(33)$ & $136(22)$ & $40(56)$ & $101(66)$ & $<0.001$ \\
\hline History of arrhythmia & $104(12)$ & $47(8)$ & $18(25)$ & $39(26)$ & $<0.001$ \\
\hline Atrial fibrillation & $95(91)$ & $44(94)$ & $51(89)$ & $51(89)$ & \\
\hline Atrial flutter & $7(7)$ & $2(4)$ & $5(9)$ & $5(9)$ & \\
\hline Ventricular tachycardia & $2(2)$ & $1(2)$ & $1(2)$ & $1(2)$ & \\
\hline History of ACS & $89(11)$ & $35(6)$ & $15(21)$ & $39(26)$ & $<0.001$ \\
\hline History of ischaemic stroke, including TIA & $75(9)$ & $42(7)$ & $11(15)$ & $22(14)$ & 0.002 \\
\hline History of heart failure & $60(7)$ & $13(2)$ & $14(19)$ & $33(22)$ & $<0.001$ \\
\hline History of peripheral artery diseases & $38(5)$ & $10(2)$ & $7(10)$ & $21(14)$ & $<0.001$ \\
\hline History of CABG & $10(1)$ & $3(0)$ & $5(7)$ & $2(1)$ & $<0.001$ \\
\hline History of stable angina & $8(1)$ & $6(1)$ & $2(3)$ & - & 0.14 \\
\hline History of haemorrhagic stroke & $5(1)$ & $2(0)$ & $1(1)$ & $2(1)$ & 0.15 \\
\hline Other CV findingsł & $115(14)$ & $50(8)$ & $11(15)$ & $54(36)$ & $<0.001$ \\
\hline ECG at admission & $811(97)$ & $592(96)$ & $72(100)$ & $147(97)$ & 0.28 \\
\hline Long QTc interval $\geq 500 \mathrm{~ms}$ & $13(2)$ & $6(1)$ & $3(4)$ & $4(3)$ & 0.05 \\
\hline Chest CT scan & $165(20)$ & $108(18)$ & $15(21)$ & $42(28)$ & 0.02 \\
\hline COVID-19 lung opacity/infiltration & $151(18)$ & $100(16)$ & $12(16)$ & $39(26)$ & 0.02 \\
\hline
\end{tabular}

Data are $\mathrm{n}(\%)$ or median (Q1-Q3). Except for age (Kruskal-Wallis test), all $\mathrm{p}$ values are according to $\chi^{2}$ test or Fisher's exact test.

*Excluding cardiovascular death.

†Obesity defined as $\mathrm{BMI} \geq 30 \mathrm{~kg} / \mathrm{m}^{2}$ (missing BMl: $\mathrm{n}=80$ ).

¥Moderate to severe valvulopathy, pacemaker, defibrillator, valvular replacement, cardiac resynchronisation therapy device and heart transplantation.

ACS, acute coronary syndrome; BMI, body mass index; CABG, coronary artery by-pass graft; CV, cardiovascular; GI, gastrointestinal; MACE, major adverse cardiovascular event; TIA, transitory ischaemic attack. 
Table 2 Clinical outcomes

\begin{tabular}{|c|c|c|c|c|}
\hline Variable & All patients* $n=839$ & $\begin{array}{l}\text { No history of CVD* } \\
n=562(67 \%)\end{array}$ & $\begin{array}{l}\text { History of CVD* } \\
n=277(33 \%)\end{array}$ & $P$ value \\
\hline Composite outcome (death or MACE) & $225(27)$ & $83(15)$ & $142(51)$ & $<0.001$ \\
\hline In-hospital death (all-cause) & $152(18)$ & $51(9)$ & $101(36)$ & $<0.001$ \\
\hline MACE & $149(18)$ & $43(8)$ & $106(38)$ & $<0.001$ \\
\hline Heart failure & $89(11)$ & $18(3)$ & $71(26)$ & $<0.001$ \\
\hline Major arrhythmia & $45(5)$ & $23(4)$ & $22(8)$ & 0.03 \\
\hline Non-fatal MI (STEMI, NSTEMI) & $16(2)$ & $4(1)$ & $12(4)$ & $<0.001$ \\
\hline Non-fatal stroke & $10(1)$ & $4(1)$ & $6(2)$ & 0.090 \\
\hline CV death & $55(7)$ & $7(1)$ & $48(17)$ & $<0.001$ \\
\hline Myocarditis & $3(0)$ & $2(0)$ & $1(0)$ & 1 \\
\hline Venous thrombotic complications $\dagger$ & $35(4)$ & $25(4)$ & $10(4)$ & 0.70 \\
\hline \multicolumn{5}{|l|}{ Hospitalisation } \\
\hline Length of stay (days) & $10(6-16)$ & $9(5-14)$ & $12(7-20)$ & $<0.001$ \\
\hline Rehabilitation & $142(17)$ & $75(13)$ & $67(24)$ & $<0.001$ \\
\hline Length of stay (days) & $16(10-24)$ & $16(10-25)$ & $15(10-23)$ & 0.70 \\
\hline ICU stay & $102(12)$ & $73(13)$ & $29(10)$ & 0.35 \\
\hline Length of stay (days) & $12(8-17)$ & $12(8-17)$ & $12(6-17)$ & 0.40 \\
\hline Invasive ventilation & $93(91)$ & $68(93)$ & $25(86)$ & \\
\hline Duration (days) & $10(7-15)$ & $10(8-15)$ & $10(7-12)$ & \\
\hline Dialysis & $7(7)$ & $4(5)$ & $3(10)$ & \\
\hline ECMO & $11(11)$ & $8(11)$ & $3(10)$ & \\
\hline IMCU stay & $135(16)$ & $84(15)$ & $51(18)$ & 0.24 \\
\hline Length of stay (days) & $4(2-6)$ & $3(2-5)$ & $4(2-6)$ & 0.43 \\
\hline
\end{tabular}

Except for lengths of stay (Welch Student test), all $p$ values are according to $\chi^{2}$ test or Fisher's exact test.

${ }^{*}$ Data are $\mathrm{n}(\%)$ or median (Q1-Q3).

†Venous thrombotic complications include: pulmonary embolism, portal vein thrombosis and deep vein thrombosis.

ECMO, extracorporeal membrane oxygenation; ICU, intensive care unit; IMCU, intermediate care unit; MACE, major adverse cardiovascular events.

reported in the online supplemental material). An ECG at admission was performed in 811 patients $(97 \%)$, of which 297 (37\%) were abnormal. The most common arrhythmia detected was atrial fibrillation. Of note, among non-survivors, only four patients had a long QTcorrected interval ( $\geq 500 \mathrm{~ms})$. Of note, $165(20 \%)$ patients had a chest CT scan of whom 151 had patterns consistent with COVID-19 findings (lung opacity and infiltration). Laboratory values and medication at admission are reported in the online supplemental tables 1 and 2.

\section{Clinical outcomes}

The median length of hospital stay was 10 days (Q1Q3, 6-16), 152 patients (18\%) died in hospital, 615 $(73 \%)$ were discharged without CV complications and $72(9 \%)$ were discharged with MACE, the most common being heart failure (table 2). Patients with history of CVD experienced more in-hospital death or MACE; among the 277 patients with history of CVD, $141(51 \%)$ died or developed a MACE during their hospitalisation, compared with $83 / 562(15 \%)$ patients without history of CVD $(\mathrm{OR}=6.0 \quad(95 \%$ CI
4.3 to 8.4$), \mathrm{p}<0.001)$. In addition, considering separately, all-cause in-hospital death, MACE, non-fatal MI, arrhythmia, heart failure, non-fatal stroke and CV death were all more frequent in patients with history of CVD. In total, only three patients presented a myocarditis and $35(4 \%)$ had a venous thrombotic complication. Total length of hospitalisation was longer for patients with CVD as compared with those without CVD (median of 12 days vs 9 days, respectively, $\mathrm{p}$ value $<0.001$ ), as was the need of rehabilitation stay (24\% vs $13 \%$, respectively, p value $<0.001$ ). Overall, 102 patients $(12 \%)$ were transferred to the ICU and $135(16 \%)$ to an IMCU, with no statistical difference in risk of admission or in length of stay according to history of CVD.

In multivariate analyses (table 3), history of CVD remained an independent risk factor of death or MACE (adjusted OR=2.4, 95\% CI 1.6 to 3.6). Other factors were found to be independently associated with an increased risk of composite outcome were age (adjusted OR for a 10-year increase: 2.2, 95\% CI 
Table 3 Composite outcome (in-hospital death or in-hospital MACE)

\begin{tabular}{lllllc}
\hline Variable & $\begin{array}{l}\text { No events* } \\
\text { (n=615) }\end{array}$ & $\begin{array}{l}\text { Composite outcome* } \\
(\mathbf{n = 2 2 4 )}\end{array}$ & $\begin{array}{l}\text { Crude OR } \\
\text { (95\% Cl) }\end{array}$ & $\begin{array}{l}\text { Adjusted OR } \\
\text { (95\% Cl) }\end{array}$ & P value \\
\hline History of CV disease & $136(22 \%)$ & $141(63 \%)$ & $6.0(4.3$ to 8.4$)$ & $2.4(1.6$ to 3.5$)$ & $<0.001$ \\
\hline Age (per 10 years) & $60(50-75)$ & $82(74-88)$ & $2.3(2.0$ to 2.7$)$ & $2.2(1.9$ to 2.6$)$ & $<0.001$ \\
\hline Male gender & $321(52 \%)$ & $132(59 \%)$ & $1.3(.97$ to 1.8$)$ & $1.6(1.1$ to 2.3$)$ & 0.02 \\
\hline Lung opacity/infiltration & $100(16 \%)$ & $51(23 \%)$ & $1.5(1.0$ to 2.2$)$ & $1.9(1.2$ to 3$)$ & 0.01 \\
\hline Hypertension & $249(40 \%)$ & $143(64 \%)$ & $2.6(1.9$ to 3.6$)$ & $0.87(0.58$ to 1.3$)$ & 0.50 \\
\hline Obesity† & $153 / 544(28 \%)$ & $53 / 215(25 \%)$ & $0.84(0.58$ to 1.2$)$ & - & - \\
\hline Dyslipidaemia & $131(21 \%)$ & $74(33 \%)$ & $1.8(1.3$ to 2.6$)$ & $0.89(0.58$ to 1.3$)$ & 0.57 \\
\hline Diabetes & $105(17 \%)$ & $64(29 \%)$ & $1.9(1.4$ to 2.8$)$ & $1.5(0.95$ to 2.3$)$ & 0.08 \\
\hline Smoking & $26(4 \%)$ & $11(5 \%)$ & $1.2(0.55$ to 2.3$)$ & $1.5(0.6$ to 3.4$)$ & 0.37 \\
\hline COPD & $22(4 \%)$ & $27(12 \%)$ & $3.7(2.1$ to 6.7$)$ & $2.1(1.1$ to 4.2$)$ & 0.03 \\
\hline OSA & $46(7 \%)$ & $23(10 \%)$ & $1.4(0.82$ to 2.4$)$ & $1.4(0.7$ to 2.6$)$ & 0.28 \\
\hline
\end{tabular}

*Data are $\mathrm{n}(\%)$ or median (Q1-Q3).

†Missing BMI: $\mathrm{n}=80$.

BMI, body mass index; COPD, chronic obstructive pulmonary disease; CV, cardiovascular; MACE, major adverse cardiovascular event; OSA, obstructive sleep apnea.

1.9 to 2.6 ), male gender (adjusted OR 1.6, 95\% CI 1.1 to 2.3), lung opacity/infiltration associated with COVID-19 injury and a history of COPD (adjusted OR $2.1 ; 95 \%$ CI 1.1 to 4.2 ). If one considers death-only as an outcome (table 4), patients with history of CVD were at higher risk (adjusted $\mathrm{OR}=2.9,95 \%$ CI 1.7 to 5 ), as were older patients (adjusted OR for a 10-year increase: $2.5,95 \%$ CI 2.0 to 3.2), males (adjusted OR $1.6,95 \%$ CI 0.98 to 2.6 ) and patients with elevated CRP at admission (adjusted OR for a 10-unit increase: 1.1; $95 \%$ CI 1.1 to 1.2 ). Similar results were observed in sensitivity analyses including obesity and an increased AST/ALT ratio in the models (online supplemental table 3).

Table 4 Patient characteristics according to survival outcome

\begin{tabular}{|c|c|c|c|c|c|}
\hline Variable & $\begin{array}{l}\text { Survived (with or without MACE)* } \\
(\mathrm{n}=687)\end{array}$ & $\begin{array}{l}\text { Died* }^{*} \\
(n=152)\end{array}$ & $\begin{array}{l}\text { Crude OR } \\
(95 \% \mathrm{Cl})\end{array}$ & $\begin{array}{l}\text { Adjusted OR } \\
(95 \% \mathrm{Cl})\end{array}$ & $P$ value \\
\hline History of CVD & $176(26)$ & $101(66)$ & 5.7 (4.0 to 8.4$)$ & 2.9 (1.7 to 5.0$)$ & $<0.001$ \\
\hline Age (per 10 years) & $62(52-77)$ & $84(76-88)$ & 2.4 (2.0 to 2.8$)$ & 2.5 (2.0 to 3.2 ) & $<0.001$ \\
\hline Male gender & $357(52)$ & $96(63)$ & 1.6 (1.1 to 2.3$)$ & 1.6 (0.98 to 2.6 ) & 0.059 \\
\hline Lung opacity/infiltration & $112(16)$ & $39(26)$ & 1.8 (1.2 to 2.7$)$ & 2.5 (1.5 to 4.4$)$ & 0.001 \\
\hline Hypertension & $297(43)$ & 95 (62) & 2.2 (1.5 to 3.2$)$ & 0.80 (0.48 to 1.3$)$ & 0.40 \\
\hline Obesity† & $170 / 611(28)$ & $36 / 148(24)$ & 0.83 (0.54 to 1.3$)$ & - & \\
\hline Dyslipidaemia & $158(23)$ & $47(31)$ & 1.5 (1.0 to 2.2) & $0.67(0.40$ to 1.1$)$ & 0.12 \\
\hline Diabetes & $122(18)$ & $47(31)$ & 2.1 (1.4 to 3.1$)$ & 1.6 (0.91 to 2.6$)$ & 0.10 \\
\hline Smoking & $31(5)$ & $6(4)$ & $0.87(0.32$ to 2.0$)$ & $1.1(0.31$ to 3.1$)$ & 0.89 \\
\hline COPD & $30(4)$ & $19(13)$ & 3.1 (1.7 to 5.7$)$ & 2.0 (0.94 to 4.3$)$ & 0.07 \\
\hline OSA & $53(8)$ & $16(11)$ & 1.4 (0.76 to 2.5$)$ & 1.5 (0.68 to 3.1$)$ & 0.31 \\
\hline High Creatinine $\neq(n=817)$ & $187 / 671(28)$ & $83 / 146(57)$ & 3.4 (2.4 to 4.9$)$ & 1.3 (0.79 to 2.1$)$ & 0.30 \\
\hline CRP (per 10 units) $(n=804)$ & $50(19-91)$ & $78(41-148)$ & 1.07 (1.04 to 1.09) & $1.1(1.1$ to 1.2$)$ & $<0.001$ \\
\hline Anaemia§ $(n=814)$ & $233 / 668(35)$ & $93 / 146(64)$ & 3.3 (2.3 to 4.8$)$ & 1.5 (0.90 to 2.3$)$ & 0.13 \\
\hline AST/ALT >1 $(n=767)$ & $439 / 630(70)$ & $124 / 137$ (91) & 4.1 (2.4 to 7.9$)$ & - & \\
\hline
\end{tabular}

*Data are $\mathrm{n}(\%)$ or median (Q1-Q3).

†Missing BMI: $\mathrm{n}=80$.

$\ddagger$ Defined as creatinine $>80 \mu \mathrm{mol} / \mathrm{L}$ for females and creatinine $>106 \mu \mathrm{mol} / \mathrm{L}$ for males.

$\S A$ naemia defined as haemoglobin $<120 \mathrm{~g} / \mathrm{L}$ for women and haemoglobin $<140 \mathrm{~g} / \mathrm{L}$ for men.

ALT, alanine transaminase; AST, aspartate transaminase ; COPD, chronic obstructive pulmonary disease; CRP, C reactive protein; CVD,

cardiovascular disease; MACE, major adverse cardiovascular event; OSA, obstructive sleep apnoea. 


\section{DISCUSSION}

We found that in patients with a history of CVD, hospitalisation for COVID-19 was significantly associated with an increased risk of MACE and death. Of all MACE, new onset of heart failure was the most common adverse event ( $11 \%$ of all patients), and the most frequent cause of death was respiratory failure $(86 \%)$. Recent studies have shown the prominent role of heart failure, both as a risk factor for a severe clinical course and for mortality, that is, as a potential consequence of COVID-19 related myocardial injury. ${ }^{13} 14$

In addition, we found that history of COPD is an independent risk factor for MACE or death in patients hospitalised with COVID-19. Results from a meta-analysis have shown that in patients with history of COPD and ongoing smoking, the progression and outcomes of COVID-19 infection are more likely to be worse. In particular, the incidence of a severe course of COVID-19 in patients with pre-existing COPD was found to be fourfold higher than in individuals without COPD. ${ }^{15}$

The number of comorbidities in patients with COVID-19 is associated with higher risk of serious adverse events. ${ }^{16}$ In our population, $40 \%$ had between one and two comorbidities and $23 \%$ had $\geq 5$ comorbidities. As reported since the beginning of the pandemic, age appears to be an independent risk factor for severe courses of COVID-19 infections. ${ }^{17}$ In our study, age was also identified as an independent risk factor for MACE or death in patients hospitalised with COVID-19, and this finding highlights the crucial importance to adjust for age. Results from the vast majority of studies on COVID-19 have not been age adjusted, and therefore, the impact of age still needs to be properly quantified.

Considering gender differences, our findings indicated that male sex is an additional independent risk factor for MACE or death in patients hospitalised with COVID-19, which is consistent with the literature. ${ }^{18}$ It has been described that women appear less susceptible to viral infections, probably because of differences in innate immunity, steroid hormones and factors related to sex chromosomes. $^{19}$

Most of the laboratory values were associated with clinical outcomes (online supplemental table 1). In particular, patients experiencing MACE or death had higher levels of CRP, creatinine, increased AST/ALT ratio and leucocytes count and lower levels of haemoglobin. Higher CRP levels were significantly associated with in-hospital mortality. Interestingly, some recent studies have demonstrated that the use of dexamethasone reduces mortality in patients with COVID-19 while at the same time improving outcomes and decreasing CRP levels. ${ }^{20} 21$ Anaemia and high levels of creatinine were not identified as independent parameters associated with death. However, with an upper $95 \%$ CI greater than two, we cannot preclude those parameters as being further important laboratory features. Furthermore, the AST/ALT ratio was found to be higher in the groups of deceased patients compared with survivors, supporting the hypothesis of injury of the cardiac tissue rather than susceptibility of other organs.

Regarding CV risks factors, a large, multicentre study on hypertension and risk of COVID-19 indicated that $24 \%$ of patients with severe disease had hypertension, as compared with $14 \%$ of patients with non-severe disease, although that analysis was not adjusted for other clinical features. ${ }^{22}$ Conversely, our study shows that hypertension was not associated with MACE or death, even though almost half of the patients had hypertension $(n=392$, $47 \%$ ), and that ARBs were found to be the medication most frequently prescribed $(20 \%)$. There are still many controversies surrounding the effect of drugs inhibiting the renin-angiotensin-aldosterone system in patients with COVID-19. ${ }^{23-25}$ Mancia et $a l^{26}$ supported the hypothesis that the use of ACE inhibitors or ARBs did not affect the risk of COVID-19, nor the chances of better clinical outcomes in patients with COVID-19, compared with other antihypertensive medications. In our study, when considering all medications collected at admission, we did not find any association with the composite outcome, even after having adjusted for age. In particular, neither ACE inhibitors nor ARBs were associated with better or worse clinical outcomes (online supplemental table 2).

SARS-CoV-2 infection has also been associated with multiple direct and indirect CV complications, including myocarditis and venous thromboembolism. ${ }^{8}$ In our study, among patients without a history of CVD, $7 \%(41 / 562)$ presented a first event (either heart failure, major arrhythmia, non-fatal MI or non-fatal stroke). In total, we found only 3/839 cases of myocarditis, confirmed at cardiac MRI: acute myocarditis manifests across a variable range of clinical severity and remains a diagnostic challenge in the COVID-19 pandemic. One study suggested that $7 \%$ of COVID-19 related deaths were due to myocarditis, but the diagnosis was revealed only at autopsy. ${ }^{27}$

We found only 35/839 (4\%) cases of venous thrombotic complications, including pulmonary embolism, portal vein thrombosis and deep vein thrombosis (table 2), which remain low compared with the literature. ${ }^{28}$ However, a recent study confirmed that venous thrombotic complications occurred only in $3.6 \%$ in patients with COVID-19 admitted in a non-ICU unit versus $13.6 \%$ in ICU patients. ${ }^{29}$

Contrary to current data, we did not find obesity to be associated with death, although there was a positive trend, including for MACE. Furthermore, active smoking was not associated with death (even if 95\% CIs were extremely large).

\section{Limitations}

First, it is a monocentric observational study, and findings remain associated without causal inference, such as the role of arterial hypertension and the impact of antihypertensive medications. Although we used multivariable analyses, residual confounding and selection bias cannot be excluded. Second, several sources of bias may be present, including misclassification of some items. In particular, 
smoking status was determined from clinical charts, without direct elicitation with validated instruments with patients: this could explain the relatively small number of active smokers identified in our study. Third, we did not distinguish between type 1 and type 2 MI, but instead we considered altogether non-fatal MI. The reason for this is because we took the information of presence or absence of MI from the discharge letter, where the type of MI during hospitalisation was not specified. Lastly, there was a significant amount of missing data regarding some demographic parameters, such as patient's height.

\section{CONCLUSION}

Our results confirm that hospitalised patients with COVID-19 and with a history of CVD are at increased risk of heart failure, arrhythmia, non-fatal MI and death compared with those without a history of CVD. Older age, male sex and COPD were independent risk factors of in-hospital death or MACE. When considering allcause in-hospital death only, we found that in patients with COVID-19, the presence of a history of CVD, older age, male sex and elevated CRP levels on admission were all independent risks factors. More preventive measures should be taken in patients with underlying CVD, as well as treatment optimisation, to reduce the risk of COVID-19 complications.

\section{Author affiliations \\ ${ }^{1}$ Department of Cardiology, University Hospitals of Geneva Department of Medical Specializations, Geneva, Switzerland \\ ${ }^{2}$ Department of Health and Community Medicine, University of Geneva, Geneva, Switzerland \\ ${ }^{3}$ Intensive Care Division, Department of Acute Medicine, University Hospitals of Geneva, Oakland, California, USA \\ ${ }^{4}$ Department of Internal Medicine, University Hospitals of Geneva, Geneva, Switzerland \\ ${ }^{5}$ Division of Clinical Pharmacology and Toxicology, Department of Anesthesiology, Clinical Pharmacology, Intensive Care and Emergency Medicine, University Hospitals of Geneva, Geneva, Switzerland \\ ${ }^{6}$ Department of Laboratory Medicine and Pathology, Lausanne University Hospital (CHUV) and University of Lausanne, Lausanne, Switzerland}

Acknowledgements Special thanks to Maelle Achard, Sandra Handgraaf, Philippe Sigaud, Sandrine Brader, Anne Bevand and Aurélie Schneider-Paccot for data collection and for database management. Many thanks to Nicolas Dupuy and Abdullah Al-Awadhi for their help in collecting ECGs in intensive care unit patients. Special gratitude is expressed to Aliki Buhayer (Prism Scientific Sàrl; www. prismscientific.ch) for medical writing support.

Contributors All authors have contributed equally to the planning, conduct and reporting of the study. ET is the responsible for the overall content as guarantor.

Funding The authors have not declared a specific grant for this research from any funding agency in the public, commercial or not-for-profit sectors.

Competing interests None declared.

Patient consent for publication Not required.

Ethics approval The study has been approved by the Ethical Committee of Geneva, Switzerland (Commission Cantonale d'Ethique de la Recherche sur l'être humain, protocol,\# 2020-00610) and comply with the Declaration of Helsinki.

Provenance and peer review Not commissioned; externally peer reviewed.

Data availability statement All the raw data presented in this article are available on reasonable request to elena.tessitore@hcuge.ch, as well as the protocol of the study. No supplemental unpublished data will be given. Data are reusable on specific request. ET is the grantor of these data.

Open access This is an open access article distributed in accordance with the Creative Commons Attribution Non Commercial (CC BY-NC 4.0) license, which permits others to distribute, remix, adapt, build upon this work non-commercially, and license their derivative works on different terms, provided the original work is properly cited, appropriate credit is given, any changes made indicated, and the use is non-commercial. See: http://creativecommons.org/licenses/by-nc/4.0/.

\section{ORCID iDs}

Elena Tessitore http://orcid.org/0000-0003-1680-0152

Cedric Follonier http://orcid.org/0000-0001-6848-4978

\section{REFERENCES}

1 WHO Director-General's opening remarks at the media briefing on COVID-19, 2020. Available: https://www.who.int/dg/speeches/detail/ who-director-general-s-opening-remarks-at-the-media-briefing-oncovid-19-11-march-2020

2 European Centre for Disease Prevention and Control. COVID-19 situation update worldwide. Available: www.ecdc.europa.eu/en/ geographical-distribution-2019-ncov-cases

3 Xiong T-Y, Redwood S, Prendergast B, et al. Coronaviruses and the cardiovascular system: acute and long-term implications. Eur Heart J 2020;41:1798-800.

4 ACC clinical Bulletin focuses on cardiac implications of coronavirus (COVID-19). Available: https://www.acc.org/latest-in-cardiology/ articles/2020/02/13/12/42/acc-clinical-bulletin-focuses-on-cardiacimplications-of-coronavirus-2019-ncov

5 ESC guidance for the diagnosis and management of CV disease during the COVID-19 pandemic. Available: https://www.escardio. org/Education/COVID-19-and-Cardiology/ESC-COVID-19Guidance\#p03

6 Epidemiology Working Group for NCIP Epidemic Response, Chinese Center for Disease Control and Prevention. [The epidemiological characteristics of an outbreak of 2019 novel coronavirus diseases (COVID-19) in China]. Zhonghua Liu Xing Bing Xue Za Zhi 2020;41:145-51.

7 Shi S, Qin M, Cai Y, et al. Characteristics and clinical significance of myocardial injury in patients with severe coronavirus disease 2019. Eur Heart J 2020;41:2070-9.

8 Driggin E, Madhavan MV, Bikdeli B, et al. Cardiovascular considerations for patients, health care workers, and health systems during the COVID-19 pandemic. J Am Coll Cardiol 2020;75:2352-71.

9 Grover A, Oberoi M. A systematic review and meta-analysis to evaluate the clinical outcomes in COVID-19 patients on angiotensinconverting enzyme inhibitors or angiotensin receptor blockers. Eur Heart J Cardiovasc Pharmacother 2021;7:148-57.

10 WHO Guideline Development Group for Clinical Management of COVID-19. Clinical management of COVID-19. Interim guidance. Available: https://www.who.int/publications/i/item/clinicalmanagement-of-covid-19

11 Ponikowski P, Voors AA, Anker SD, et al. 2016 ESC Guidelines for the diagnosis and treatment of acute and chronic heart failure: The Task Force for the diagnosis and treatment of acute and chronic heart failure of the European Society of Cardiology (ESC)Developed with the special contribution of the Heart Failure Association (HFA) of the ESC. Eur Heart J 2016;37:2129-200.

12 Thygesen K, Alpert JS, Jaffe AS, et al. Fourth universal definition of myocardial infarction (2018). J Am Coll Cardiol 2018;72:2231-64.

13 Inciardi RM, Adamo M, Lupi L, et al. Characteristics and outcomes of patients hospitalized for COVID-19 and cardiac disease in northern Italy. Eur Heart J 2020;41:1821-9.

14 Madjid M, Safavi-Naeini P, Solomon SD, et al. Potential effects of coronaviruses on the cardiovascular system: a review. JAMA Cardiol 2020;5:831-40.

15 Zhao Q, Meng M, Kumar R, et al. The impact of COPD and smoking history on the severity of COVID-19: a systemic review and metaanalysis. J Med Virol 2020;92:1915-21.

16 Guan W-jie, Liang W-hua, Zhao Y. Comorbidity and its impact on 1590 patients with COVID-19 in China: a nationwide analysis. European Respiratory Journal 2020;55:2000547.

17 Onder G, Rezza G, Brusaferro S. Case-fatality rate and characteristics of patients dying in relation to COVID-19 in Italy. JAMA 2020;323:1775-6.

18 Gebhard C, Regitz-Zagrosek V, Neuhauser HK, et al. Impact of sex and gender on COVID-19 outcomes in Europe. Biol Sex Differ 2020;11:29. 
19 Conti P, Younes A. Coronavirus COV-19/SARS-CoV-2 affects women less than men: clinical response to viral infection. J Biol Regul Homeost Agents 2020;34:339-43.

20 Selvaraj V, Dapaah-Afriyie K, Finn A, et al. Short-term dexamethasone in Sars-CoV-2 patients. R I Med J 2020;103:39-43.

21 The RECOVERY Collaborative Group. Dexamethasone in hospitalized patients with Covid-19. N Engl J Med 2021;384:693-704.

22 Guan W-J, Ni Z-Y, Hu Y, et al. Clinical characteristics of coronavirus disease 2019 in China. N Engl J Med 2020;382:1708-20.

23 South AM, Tomlinson L, Edmonston D, et al. Controversies of reninangiotensin system inhibition during the COVID-19 pandemic. Nat Rev Nephrol 2020;16:305-7.

24 Vaduganathan M, Vardeny O, Michel T, et al. Renin-AngiotensinAldosterone system inhibitors in patients with Covid-19. N Engl J Med 2020;382:1653-9.
25 Reynolds HR, Adhikari S, Pulgarin C, et al. Renin-AngiotensinAldosterone system inhibitors and risk of Covid-19. N Engl J Med 2020;382:2441-8.

26 Mancia G, Rea F, Ludergnani M, et al. Renin-AngiotensinAldosterone system blockers and the risk of Covid-19. N Engl J Med 2020;382:2431-40.

27 Ruan Q, Yang K, Wang W, et al. Clinical predictors of mortality due to COVID-19 based on an analysis of data of 150 patients from Wuhan, China. Intensive Care Med 2020;46:846-8.

28 Lodigiani C, lapichino G, Carenzo L, et al. Venous and arterial thromboembolic complications in COVID-19 patients admitted to an academic hospital in Milan, Italy. Thromb Res 2020;191:9-14.

29 Bilaloglu S, Aphinyanaphongs $\mathrm{Y}$, Jones S, et al. Thrombosis in hospitalized patients with COVID-19 in a new York City health system. JAMA 2020;324:799-801. 